\title{
Effects of hormone therapy on brain structure
}

\author{
A randomized controlled trial \\ OPEN
}

Kejal Kantarci, MD, MS

Nirubol Tosakulwong

Timothy G. Lesnick, MS

Samantha M. Zuk

Jeffrey L. Gunter, PhD

Carey E. Gleason, $\mathrm{PhD}$

Whitney Wharton, PhD

N. Maritza Dowling, PhD

Prashanthi Vemuri, PhD

Matthew L. Senjem, MS

Lynne T. Shuster, MD

Kent R. Bailey, PhD

Walter A. Rocca, MD, $\mathrm{MPH}$

Clifford R. Jack, Jr., MD

Sanjay Asthana, MD

Virginia M. Miller, PhD

Correspondence to

Dr. Kantarci:

kantarci.kejal@mayo.edu

Supplemental data at Neurology.org

\section{ABSTRACT}

Objective: To investigate the effects of hormone therapy on brain structure in a randomized, double-blinded, placebo-controlled trial in recently postmenopausal women.

Methods: Participants (aged 42-56 years, within 5-36 months past menopause) in the Kronos Early Estrogen Prevention Study were randomized to (1) $0.45 \mathrm{mg} / \mathrm{d}$ oral conjugated equine estrogens (CEE), (2) $50 \mu \mathrm{g} / \mathrm{d}$ transdermal $17 \beta$-estradiol, or (3) placebo pills and patch for 48 months. Oral progesterone $(200 \mathrm{mg} / \mathrm{d})$ was given to active treatment groups for 12 days each month. MRI and cognitive testing were performed in a subset of participants at baseline, and at 18, 36, and 48 months of randomization ( $n=95$ ). Changes in whole brain, ventricular, and white matter hyperintensity volumes, and in global cognitive function, were measured.

Results: Higher rates of ventricular expansion were observed in both the CEE and the $17 \beta$-estradiol groups compared to placebo; however, the difference was significant only in the CEE group $(p=0.01)$. Rates of ventricular expansion correlated with rates of decrease in brain volume $(r=$ $-0.58 ; p \leq 0.001)$ and with rates of increase in white matter hyperintensity volume $(r=0.27 ; p=$ 0.01 ) after adjusting for age. The changes were not different between the CEE and $17 \beta$-estradiol groups for any of the MRI measures. The change in global cognitive function was not different across the groups.

Conclusions: Ventricular volumes increased to a greater extent in recently menopausal women who received CEE compared to placebo but without changes in cognitive performance. Because the sample size was small and the follow-up limited to 4 years, the findings should be interpreted with caution and need confirmation.

Classification of evidence: This study provides Class I evidence that brain ventricular volume increased to a greater extent in recently menopausal women who received oral CEE compared to placebo. Neurology ${ }^{\circledR}$ 2016;87:887-896

\section{GLOSSARY}

CEE $=$ conjugated equine estrogens; FLAIR $=$ fluid-attenuated inversion recovery; KEEPS $=$ Kronos Early Estrogen Prevention Study; WHIMS = Women's Health Initiative Memory Study; WMH = white matter hyperintensity.

Hormone therapy with conjugated equine estrogens (CEE) and medroxyprogesterone acetate initiated later in menopause increased the risk of dementia in the Women's Health Initiative Memory Study (WHIMS). ${ }^{1}$ Whether alternative formulations of hormone therapy can preserve neuronal integrity and decrease the risk of dementia when administered early in menopause remains controversial. ${ }^{2-10}$ Determining the effects of hormone therapy during the early postmenopausal years on the risk of dementia would require decades of follow-up. However, noninvasive imaging markers related to cognitive health have been suggested as short-term surrogate outcomes to assess the effects of menopausal hormone therapy on the brain. Thus, age-associated changes in

\footnotetext{
From the Departments of Radiology (K.K., S.M.Z., J.L.G., P.V., M.L.S., C.R.J.), Health Sciences Research (N.T., T.G.L., K.R.B., W.A.R.), Internal Medicine (L.T.S.), Neurology (W.A.R.), and Surgery and Physiology and Biomedical Engineering (V.M.M.), Mayo Clinic, Rochester, MN; Department of Medicine (C.E.G., S.A.), School of Medicine and Public Health, University of Wisconsin and Geriatric Research, Education and Clinical Center, William S. Middleton Memorial, Veterans' Hospital, Madison, WI; Department of Neurology (W.W.), Emory University, Atlanta, GA; and Department of Biostatistics and Medical Informatics (N.M.D.), University of Wisconsin, Madison.

Go to Neurology.org for full disclosures. Funding information and disclosures deemed relevant by the authors, if any, are provided at the end of the article. The Article Processing Charge was paid by the authors.

This is an open access article distributed under the terms of the Creative Commons Attribution-NonCommercial-NoDerivatives License 4.0 (CC BY-NC-ND), which permits downloading and sharing the work provided it is properly cited. The work cannot be changed in any way or used commercially.
} 
brain structure on MRI can be used to measure the effects of estrogens on the brains of postmenopausal women.

The Kronos Early Estrogen Prevention Study (KEEPS) tested the hypothesis that menopausal hormone therapy administered early after the onset of menopause would slow progression of atherosclerosis. ${ }^{11}$ However, hormone therapy in KEEPS did not affect progression of atherosclerosis $^{12}$ or cognitive function ${ }^{13}$ within the 4 years of hormone therapy. We report here the results of an ancillary study to KEEPS, conducted to determine the effects of oral CEE and transdermal $17 \beta$-estradiol therapy on changes in structural brain MRI over 4 years. The ventricular volume change was chosen as the primary outcome measure because it was the most reliable measure of the change in brain structure associated with aging and cognitive function. ${ }^{14}$ The secondary outcome measures included changes in whole brain and white matter hyperintensity (WMH) volumes.

METHODS Participants. KEEPS was a multicenter, randomized, double-blinded, placebo-controlled clinical trial in recently menopausal women $(\mathrm{n}=727)$. Participants enrolled in KEEPS were between 42 and 59 years of age, within 5 to 36 months past their last menses, and were in good cardiovascular health. ${ }^{11}$ An ancillary MRI study to KEEPS was conducted from February 2006 through August 2011 at the Mayo Clinic to investigate the effects of hormone treatment on brain structure. Exclusion criteria for enrollment in the ancillary KEEPS-MRI study were MRI contraindications for safety and neurologic disorders.

Baseline MRI examinations and cognitive testing were completed following randomization but with concealed allocation and before treatment initiation. The treatments were as follows: (1) oral CEE $(0.45 \mathrm{mg} / \mathrm{d}$; Premarin, Pfizer, New York, NY); (2) transdermal $17 \beta$-estradiol (17ß-estradiol skin patch, $50 \mu \mathrm{g} / \mathrm{d}$; Climara, Bayer HealthCare Pharmaceuticals Inc., Wayne, NJ); or (3) placebo pills and patch. Estrogens were administered through 2 different routes, oral or transdermal, because of the increased risk of venous thrombosis with oral estrogens. It was hypothesized that transdermal $17 \beta$-estradiol would have a different effect on risk factors for atherosclerosis and thromboembolic disease compared to oral CEE. Progesterone was given orally (micronized progesterone, $200 \mathrm{mg} / \mathrm{d}$; Prometrium, AbbVie Inc., North Chicago, IL) for 12 days at the beginning of each month to both active treatment groups to protect the endometrium. Follow-up MRI examinations and cognitive testing were performed at 18 months (estrogen-only phase), 36 months (progesterone phase; to determine whether there would be an effect on the trajectory of change in outcome measures due to progesterone), and at 48 months (estrogen-only phase). ${ }^{11}$

Standard protocol approvals, registrations, and patient consents. The present study (NCT00154180; https://clinicaltrials.gov/ct2/show/NCT00154180) was approved by the Mayo Clinic institutional review board (no. 224104). All participants provided written informed consent.
Cognitive testing. A confirmatory factor analysis was used to assess the underlying structure of baseline cognitive data from the KEEPS cognitive and affective study, and to derive summary scores $(\mathrm{n}=662) .{ }^{15}$ Using standard criteria for model fit, the cognitive variables were summarized in 4 specific independent domains and a general domain representing global cognitive function. ${ }^{16}$

Magnetic resonance imaging. MRI studies were performed on a single 1.5-tesla system, with an 8-channel phased-array coil (GE Healthcare, Waukesha, WI). A 3-dimensional, magnetizationprepared rapid-acquisition gradient echo sequence was acquired for volumetric analysis, and fluid-attenuated inversion recovery (FLAIR) MRI was acquired for quantification of WMH volume. Changes in ventricle and whole brain volumes were calculated automatically from each registered magnetizationprepared rapid-acquisition gradient echo scan pair using the boundary shift integral and expressed in cubic centimeters of volume change from baseline for each follow-up time point as previously described. ${ }^{17}$ The boundary shift integral is designed to monitor brain structural changes and treatment effects in clinical trials of Alzheimer disease. ${ }^{18}$

WMH volumes were derived from semiautomated segmentation of FLAIR images as previously described. ${ }^{19}$ Briefly, WMH on FLAIR images were segmented using an automated slice-based seed initialization and region growing method. A trained image analyst (S.Z.), blinded to treatment group as well as to the sequence of the follow-up scans, inspected the segmented WMH mask overlaid on the FLAIR image. Every segmented image was visually compared to the unprocessed FLAIR image and false-positive WMH labels resulting from artifacts were edited to be excluded from the WMH mask. The WMH masks on follow-up scans were also visually compared to the baseline WMH mask for consistent editing of the artifacts. One of the baseline FLAIR scans failed quality control and was therefore excluded from the analysis. Longitudinal change in WMH was expressed in cubic centimeters of volume change from baseline for each follow-up MRI.

Statistical analysis. Baseline characteristics were compared among groups using analysis of variance followed by Tukey pairwise tests, 2-sample $t$ tests, or Fisher exact tests, as appropriate. Changes in the outcomes from baseline were shown using plots of mean values and their associated $95 \%$ confidence intervals at each time point. Associations between the outcome variables at 48 months were shown using scatterplots with Pearson correlation coefficients adjusted for age. In a secondary analysis, the percent change in the whole brain, ventricular, and WMH volumes over 18, 36, and 48 months in CEE and $17 \beta$-estradiol groups was compared to placebo by $t$ tests.

Ventricular and whole brain volumes, WMH, and global cognitive score changes over time were modeled using linear mixed models as planned a priori, with each model containing time from baseline, treatment group, and time from baseline $\times$ treatment group interactions as fixed-effects predictors. These models incorporated random effects for subject-specific intercepts and slopes. Coefficient estimates with their associated $95 \%$ confidence intervals, and categories of significance were reported for these models. Treatments were compared to each other and to placebo. Treatment by time interactions were of primary interest because any treatment effect would likely manifest as a change in the trajectories over time rather than a sudden jump in the magnitude of the outcomes. Because the primary analyses on the effects of each of the 2 hormone therapies on brain structure were determined a priori, there was no adjustment for multiple comparisons in 
reporting these results. Furthermore, results from the 2 hormone therapy groups were not pooled because of the differences in formulations and route of administration.

For our primary analysis of ventricular volumes using linear mixed models, with $\alpha=0.05$ and the smallest group size of 29 for conservative estimates, there was $80 \%$ power to detect a difference in slopes over time between groups of $0.296 \mathrm{~cm}^{3}$ per year. For example, for a woman starting at the mean baseline ventricular volume of $19.6 \mathrm{~cm}^{3}$, a $1.5 \%$ increase could be detected per year because of treatment (a $2.3 \%$ increase in the volume after 18 months, $4.5 \%$ after 36 months, and $6.0 \%$ after 48 months).

RESULTS All women enrolled in KEEPS at Mayo Clinic Rochester $(\mathrm{n}=118)$ were invited to participate in the ancillary MRI study. Five participants were excluded because of neurologic disorders or MRI contraindications; 12 women declined participation. Eligible women underwent a baseline MRI ( $\mathrm{n}=101)$ before starting treatment. MRI data were analyzed for the 95 participants who repeated at least one MRI examination at $18(\mathrm{n}=92), 36(\mathrm{n}=87)$, or $48(\mathrm{n}=79)$ months (figure 1). Baseline global cognitive performance and whole brain volumes were not different among treatment and placebo groups. However, ventricular volumes were larger in the $17 \beta$ estradiol treatment group $(p=0.025)$ and WMH volumes were larger in the CEE treatment group

Figure 1 KEEPS-MRI study participation

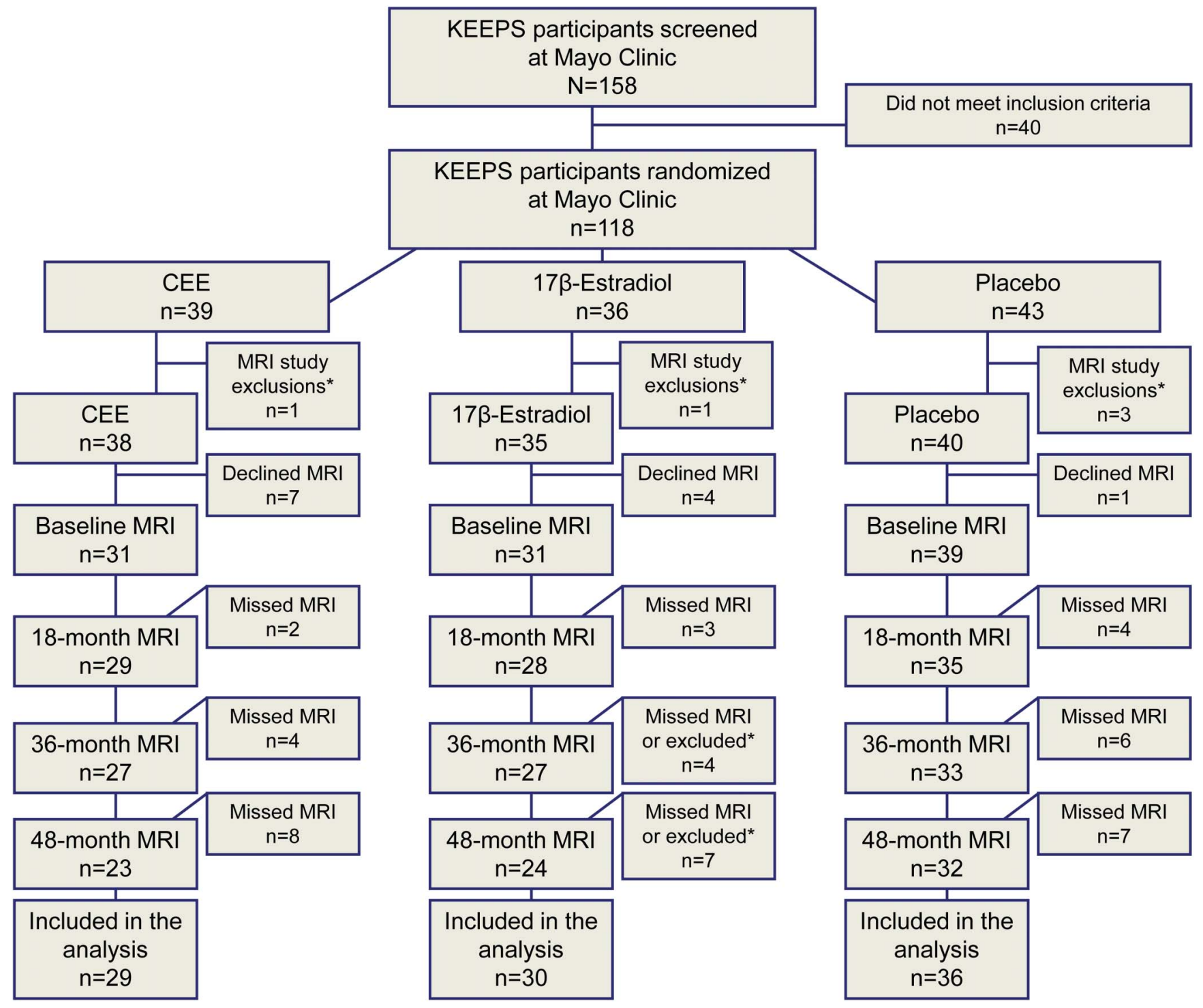

Participation and exclusions from the KEEPS-MRI study are shown. Participants who had a baseline MRI before onset of treatment and had at least one follow-up MRI at months 18, 36, or 48 were included in the analysis. *There were 5 exclusions at baseline MRI: MRI incompatible implant (CEE group); posterior fossa developmental abnormality and hydrocephalus (17 $\beta$-estradiol group); 2 participants with multiple sclerosis and one participant with a benign brain tumor (placebo group). There was an exclusion of a participant from the $17 \beta$-estradiol group who developed breast cancer after completing the 18month scan and underwent chemotherapy. Her structural MRI data at months 36 and 48 were excluded from analysis because of the potential adverse effects of chemotherapy on brain structure. One of the baseline fluid-attenuated inversion recovery scans failed quality control and therefore had to be excluded from the analysis. CEE = conjugated equine estrogens; KEEPS = Kronos Early Estrogen Prevention Study. 
( $p=0.008)$ compared to placebo at baseline after adjusting for total intracranial volume (table 1). None of the participants had silent infarcts on baseline and follow-up MRI examinations.

Whole brain volumes decreased in the $\operatorname{CEE}(p=$ $0.004)$ and the $17 \beta$-estradiol $(p=0.002)$ treatment groups, but not in the placebo group $(p=0.09)$ over 48 months. However, the decline in whole brain volume was not significantly different between the placebo and treatment groups (CEE and $17 \beta$-estradiol). Ventricular volumes increased in both the treatment (CEE and $17 \beta$-estradiol) and the placebo groups over 48 months $(p<0.001)$. Increases in ventricular volumes were greater only in the CEE treatment group compared to the placebo group $(p=0.01)$. WMH volume increased in the CEE $(p=0.004)$ and $17 \beta$-estradiol $(p=0.002)$ groups, but not in the placebo group $(p=$ 0.42 ) over 48 months. However, the increase in WMH volumes was not different when comparing the CEE $(p=0.10)$ and $17 \beta$-estradiol $(p=0.06)$ groups to the placebo group (figure 2). The results of mixed-effects models are summarized in table 2. Changes in any of the MRI measures did not differ between the CEE and $17 \beta$-estradiol groups (table e-1 at Neurology.org).

Because baseline WMH volumes were higher in the CEE group than in the placebo group, we tested whether baseline WMH modified the treatment $\times$ time interactions by adding baseline WMH and baseline $\mathrm{WMH} \times$ time to the mixed models. The parameter estimates and $p$ values for treatment $X$ time were then compared with and without the baseline adjustment to see if they differed. The primary interest was in possible effects of baseline WMH on the significant CEE vs placebo difference in ventricular volume change. After adjusting for baseline WMH, increases in ventricular volumes in the CEE treatment group remained greater than in the placebo group $(p=$ 0.011 ), but did not reach statistical significance in

Table 1 Baseline characteristics of the participants

\begin{tabular}{|c|c|c|c|}
\hline & CEE $(n=29)$ & $17 \beta$-Estradiol $(n=30)$ & Placebo $(n=36)$ \\
\hline Age, y & $53(52,54)$ & $53(52,54)$ & $53(52,54)$ \\
\hline \multicolumn{4}{|l|}{ Education } \\
\hline High school or less & $2(7)$ & $1(4)$ & $3(8)$ \\
\hline Some college/college graduate & $19(70)$ & $18(64)$ & $22(61)$ \\
\hline Some graduate/graduate & $6(22)$ & 9 (32) & $11(31)$ \\
\hline \multicolumn{4}{|l|}{ Smoking status } \\
\hline Nonsmoker & $15(68)$ & $12(55)$ & $24(73)$ \\
\hline Smoker (past or current) & $7(32)$ & $10(45)$ & $9(27)$ \\
\hline Time past menopause, mo & $21(17,25)$ & $20(17,23)$ & $17(14,20)$ \\
\hline Treatment onset past baseline MRI, d & $13(3,23)$ & $20(10,30)$ & $28(7,49)$ \\
\hline APOE $\varepsilon 4$ carrier & $4(15)$ & $13(45)$ & $7(21)$ \\
\hline Migraines & $3(10)$ & $0(0)$ & $4(11)$ \\
\hline Global cognitive function scores & $-0.19(-0.48,0.10)$ & $0.16(-0.12,0.44)$ & $0.14(-0.08,0.36)$ \\
\hline Mean systolic blood pressure, $\mathrm{mm} \mathrm{Hg}$ & $122(117,127)$ & $120(114,126)$ & $122(118,126)$ \\
\hline Mean diastolic blood pressure, $\mathrm{mm} \mathrm{Hg}$ & $77(74,80)$ & $73(70,76)$ & $76(74,78)$ \\
\hline Waist circumference, cm & $87(82,92)$ & $83(79,87)$ & $84(80,88)$ \\
\hline Body mass index, kg/m² & $28(26,30)$ & $26(25,27)$ & $27(26,28)$ \\
\hline Coronary arterial calcification present & $4(14)$ & $3(10)$ & $4(11)$ \\
\hline Carotid intima-media thickness & $0.71(0.67,0.75)$ & $0.72(0.68,0.76)$ & $0.71(0.68,0.74)$ \\
\hline Low-density lipoprotein, mg/dL & $134(124,144)$ & $137(125,149)$ & $130(119,141)$ \\
\hline High-density lipoprotein, mg/dL & $59(54,64)$ & $63(58,68)$ & $60(55,65)$ \\
\hline Triglycerides, mg/dL & $93(78,108)$ & $101(81,121)$ & $91(76,106)$ \\
\hline Whole brain volume, $\mathrm{cm}^{3}$ & $1,334(1,300,1,368)$ & $1,316(1,285,1,347)$ & $1,302(1,269,1,335)$ \\
\hline Ventricular volume, $\mathrm{cm}^{3}$ & $19.6(16.8,22.4)$ & $22.1(18.7,25.5)^{a}$ & $17.6(15.5,19.7)$ \\
\hline White matter hyperintensity volume, $\mathrm{cm}^{3}$ & $2.7(2.1,3.3)^{b}$ & $2.3(1.8,2.8)$ & $1.8(1.6,2.0)$ \\
\hline
\end{tabular}

Abbreviation: $\mathrm{CEE}=$ conjugated equine estrogens.

Data are $\mathrm{n}(\%)$ or mean (95\% confidence interval).

a Pairwise comparison to placebo $p<0.05$.

${ }^{\mathrm{b}}$ Pairwise comparison to placebo $\mathrm{p}<0.01$. 

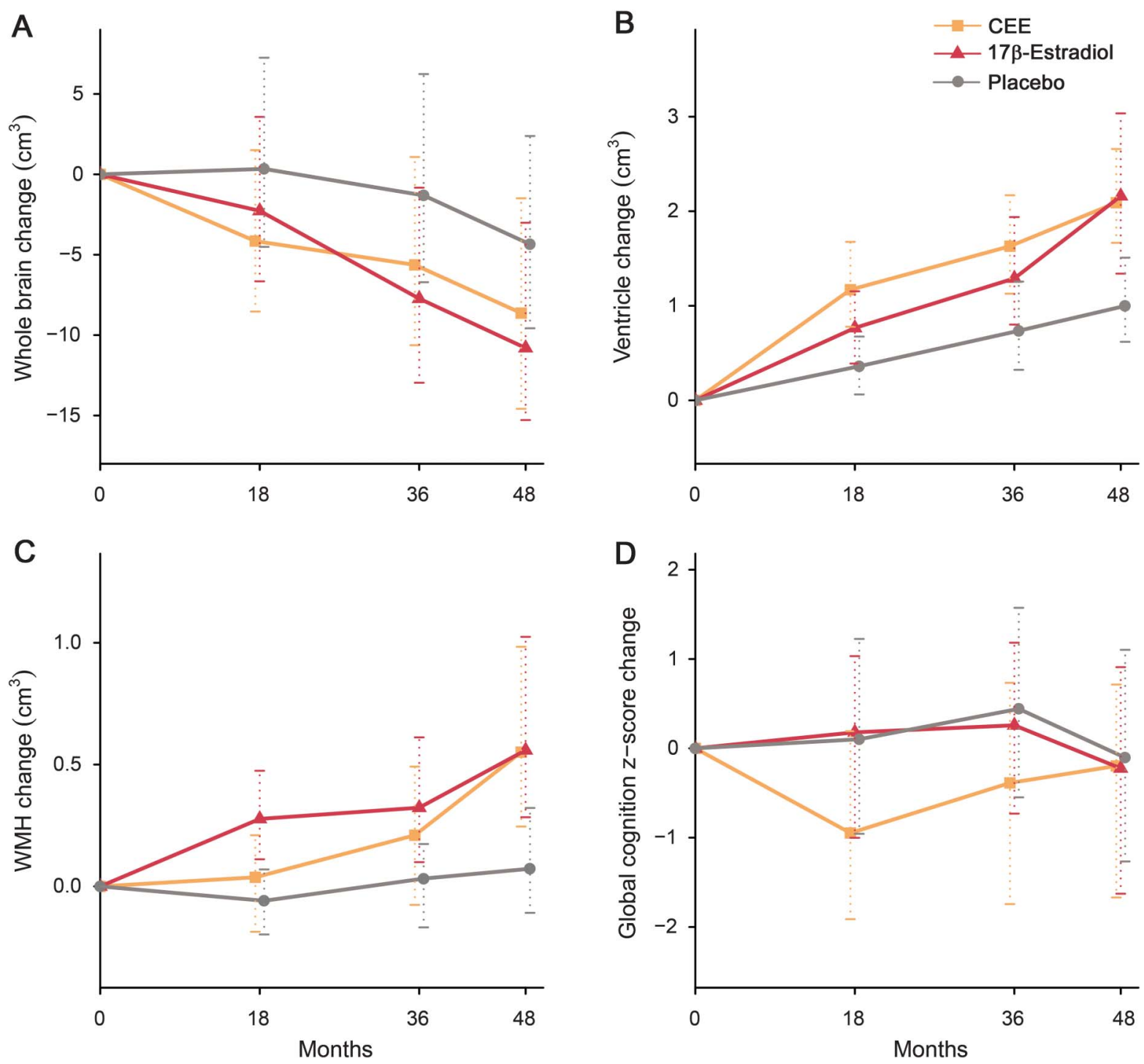

Mean change $\left(\mathrm{cm}^{3}\right)$ and $95 \%$ confidence intervals at 18, 36, and 48 months for whole brain volume (A), ventricular volume (B), and WMH volume (C). Mean change in global cognition z scores and $95 \%$ confidence intervals at 18, 36, and 48 months (D) is displayed. Increases in ventricular volumes were greater in the CEE treatment group than in the placebo group $(p=0.01)$, but not in the $17 \beta$-estradiol group compared to the placebo group $(p=0.09)$. CEE $=$ conjugated equine estrogens; $\mathrm{WMH}=$ white matter hyperintensity.

the $17 \beta$-estradiol group compared with the placebo group $(p=0.06)$ (table e-2).

Percent increases in ventricular volume from baseline to 18,36 , and 48 months were greater in the CEE group but not in the $17 \beta$-estradiol group compared to placebo at all time points. On the contrary, percent increases in WMH volume from baseline were greater in the CEE group only at 48 months and in the $17 \beta$-estradiol group only at 18 months compared to placebo (table 3).

Global cognitive function did not change in the treatment or the placebo group, and there were no differences in global cognitive change between CEE, $17 \beta$-estradiol, and placebo groups over 48 months (figure 2).
Over the 48 months of follow-up, the increase in ventricular volume correlated with the decline in whole brain volume $(r=-0.58 ; p \leq 0.001)$ and with the increase in WMH volume $(r=0.27$; $p=$ 0.01) after adjusting for age.

In the CEE group, increases in ventricular volume at 18 months correlated with timing of initiation of treatment in relation to the onset of menopause, after adjusting for age. Women who initiated hormone therapy later in menopause had greater increases in ventricular volume at 18 months $(r=0.40 ; p=$ $0.03)$. This association was weaker at 36 months $(r=0.35 ; p=0.07)$ and at 48 months $(r=0.26$; $p=0.24)$. By contrast, there were no correlations between increases in ventricular volume and timing 
Table 2 Annual change in imaging markers on mixed-effects model

$\begin{array}{llll} & \begin{array}{l}\text { Whole brain, } \mathrm{cm}^{3} \text {, estimates } \\ (95 \% \mathrm{Cl})\end{array} & \begin{array}{l}\text { Ventricle, } \mathrm{cm}^{3} \text {, estimates } \\ (95 \% \mathrm{Cl})\end{array} & \begin{array}{l}\text { WMH, } \mathbf{c m}^{3} \text {, estimates } \\ (95 \% \mathrm{Cl})\end{array} \\ \begin{array}{lll}\text { Intercept } \\ \text { Time from baseline }\end{array} & 1,303(1,273,1,333)^{\mathrm{a}} & 17.5(15.1,20)^{\mathrm{a}} & 1.78(1.39,2.17)^{\mathrm{a}} \\ \text { CEE } & -1.12(-2.43,0.19) & 0.27(0.13,0.41)^{\mathrm{a}} & 0.03(-0.04,0.09) \\ \begin{array}{l}17 \beta \text {-estradiol } \\ \text { CEE } \times \text { time from baseline }\end{array} & -1.08(-3.06,0.9) & 2.41(-1.27,6.09) & 0.85(0.26,1.43)^{\mathrm{b}} \\ \begin{array}{l}17 \beta \text {-estradiol } \times \text { time from } \\ \text { baseline }\end{array} & -1.14(-3.1,0.81) & 4.4(0.78,8.1)^{\mathrm{c}} & 0.58(-0.007,1.16) \\ \end{array}$

Abbreviations: $\mathrm{CEE}=$ conjugated equine estrogens; $\mathrm{Cl}=$ confidence interval; $\mathrm{WMH}=$ white matter hyperintensity. Linear mixed-effects models with time from baseline, treatment group, and their interaction as predictors, whole brain, ventricle, and $\mathrm{WMH}$ volume change as outcomes, and random subject-specific intercepts and slopes are reported for the CEE, $17 \beta$-estradiol, and placebo groups. Coefficient estimates with their associated $95 \% \mathrm{Cls}$ and categories of significance are reported for these models. Treatment $\times$ time interactions were of interest because any treatment effects would likely manifest as a change in the trajectories over time.

${ }^{a} p<0.001$

${ }^{\mathrm{b}} \mathrm{p} \leq 0.01$.

${ }^{c} p<0.05$.

of initiation of $17 \beta$-estradiol treatment, after adjusting for age.

DISCUSSION The major finding of this study is that the rates of increase in ventricular volumes were greater in recently menopausal women who received oral CEE therapy compared to placebo over 4 years without significant differences in changes in global cognition. Although the rates of changes in MRI measures did not differ between the CEE and $17 \beta$-estradiol groups, the rates of increase in ventricular volume did not reach statistical significance in the $17 \beta$-estradiol group, compared to placebo, probably because of our limited sample size and short follow-up. Furthermore, increases in ventricular volume over 18 months of treatment were greater in the CEE group if hormone therapy was initiated later in menopause.

It is difficult to compare the findings of the present study with the findings of other studies in the literature, because the earlier studies were conducted in older women, and the structural MRI assessments were cross-sectional and not longitudinal, and were performed many years after initiation of hormone therapy. However, given these limitations, greater rates of structural brain changes with CEE therapy compared to placebo in the present study are consistent with the finding of lower regional brain volumes in women who initiate hormone therapy at age 65 years or older in the WHIMS-MRI, when the structural MRI changes were observed after the study medications were stopped..$^{20}$ Our findings also agree with observational studies that found larger ventricular volumes in women using hormone therapies ${ }^{21,22}$ but contradict other studies that showed larger brain volumes in women who used postmenopausal hormone therapy compared to women who did not. ${ }^{23-26}$

Although measurements of both whole brain and ventricular volumes are surrogates for the change in global brain structure and correlate with each other, differences between CEE treatment and placebo groups were statistically significant when comparing the rates of ventricular volume change but not the rates of whole brain volume change. This may be attributable to the differences in noise and measurement variability. Indeed, smaller sample sizes are needed to detect treatment effects using ventricular volume change compared to whole brain volume change. ${ }^{14}$

Brain volumes quantified on MRI decrease and ventricular volumes increase during physiologic aging. ${ }^{27}$ The decrease in brain volume accelerates in cognitively normal older adults several years before they develop mild cognitive impairment ${ }^{14}$ or dementia. ${ }^{28}$ Although structural MRI changes are adequate surrogate markers for tracking the progression of preclinical neurodegenerative brain pathology many years before the onset of cognitive decline, they may not be ideal markers for detecting the effects of specific treatments that might modify brain function or pathology. ${ }^{29}$ Evidence of hormonal effects on brain structure in younger women is limited to studies in premenopausal women. Premenstrual decreases in estrogen and progesterone levels are associated with increased ventricular volumes, ${ }^{30}$ and postmenstrual increases in estrogen levels are associated with preservation of ventricular structure and even increases in hippocampal volume. ${ }^{31}$ Furthermore, larger gray matter volumes were found in oral contraceptive users compared to nonusers. ${ }^{32}$ Both cyclic increases in 


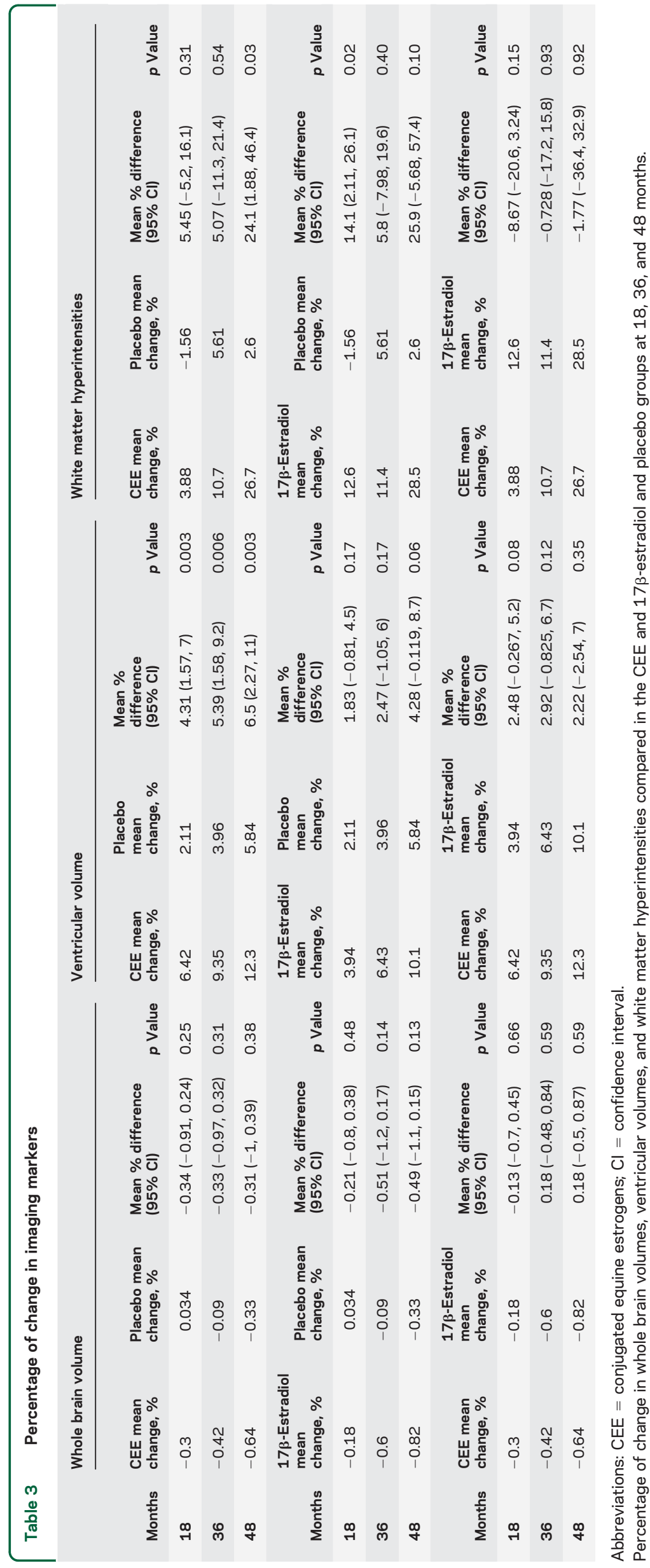

endogenous hormones and exogenous administration of hormones appear to preserve ventricular volumes and increase brain volumes in premenopausal women, in contrast to the findings of the present study with exogenous administration of hormones in postmenopausal women. Therefore, transient retention of sodium and water, which has been implicated in the premenstrual increases in ventricular volume when endogenous estrogen is low, would not explain the finding of increased ventricular volume in postmenopausal women who received estrogens.

WMH volume gradually increased only in the CEE and 17 $\beta$-estradiol treatment groups but not the placebo group. These increases in WMH volumes over 48 months correlated with the increases in ventricular volumes, suggesting that similar mechanisms may be driving both of these structural changes. Accelerated volumetric changes in brain structure and WMH are associated with cognitive decline in older adults, including ischemic small vessel disease and Alzheimer disease. ${ }^{33} \mathrm{~A}$ relationship between longitudinal increases in WMH and ventricular volumes has been reported in a cohort with atherosclerosis, slightly older than the participants of the KEEPSMRI study (mean age 53 vs 57 years) and with a high percentage of men, suggesting that cerebral small vessel disease may underlie the parallel increases in WMH and ventricular volumes. ${ }^{34}$ Although the pathologic underpinnings of WMH and ventricular volume increases in women with good cardiovascular health is unclear, there is evidence that the WMH increases in participants of the KEEPSMRI study were associated with thrombogenic microvesicles in the blood at baseline. ${ }^{19}$ Thrombogenic microvesicles are related to the progression of atherosclerosis. $^{35}$

In the CEE group, ventricular volumes increased less in women who initiated hormone therapy earlier than later in menopause, albeit only during the first 18 months. This association gradually weakened at 36 and 48 months of treatment. Since the mean time to starting CEE was 20 months past menopause (range: 5-36), the window in which hormone therapy causes less ventricular expansion appears to be limited to approximately 3 years into menopause. This time window may be associated with a gradual loss of estrogen receptor $\alpha$ in the postmenopausal brain. ${ }^{36}$

Women participating in the KEEPS-MRI study were in good cardiovascular and neurologic health, and well educated, which may limit generalization of findings to a broader population. However, in this homogeneous population of relatively healthy women, hormone therapy effects on brain structure were independent of concurrent cardiovascular or neurologic diseases. Furthermore, the sample size and the MRI changes in brain volumes were small, 
limiting statistical power. Therefore, the changes observed in the $17 \beta$-estradiol group compared to placebo may reach statistical significance with a longer duration of the study. Further investigation including larger numbers of participants and longer follow-up is warranted. Even though the treatment and placebo groups did not differ at baseline regarding cardiovascular risk factors, the CEE group had greater WMH volume than the placebo group. Some of the differences observed across groups at baseline are not surprising given the relatively small number of women included in the MRI ancillary study. Randomization does not guarantee a balanced allocation across treatment groups when the numbers are small. We found no evidence that greater WMH volume at baseline influenced the findings on ventricular volume change. We acknowledge, however, that post hoc statistical comparisons are subject to biases.

\section{Comment:}

\section{Hormone therapy in the early postmenopausal stage-} Safe for the brain?

Recent clinical trials, including the Women's Health Initiative Memory Study of Younger Women, ${ }^{1}$ provide reassurance that hormone therapy (HT) confers no cognitive risk when taken early in the postmenopausal period. In contrast, results from this ancillary neuroimaging study from the Kronos Early Estrogen Prevention Study (KEEPS) ${ }^{2}$ suggest a potential adverse effect of HTincreased ventricular volume-in women randomized to conjugated equine estrogen (CEE) early in the postmenopausal stage. These findings deserve consideration because brain changes related to Alzheimer disease are detectable earlier than neuropsychological changes.

This neuroimaging study is unique because it was embedded in a blinded randomized controlled trial, included 2 HT formulations, and repeatedly assessed multiple neuroimaging outcomes over a relatively long 4-year follow-up. Despite these strengths, the findings should be interpreted with caution because sample sizes were quite small and there were some differences in baseline neuroimaging measures across treatment groups. Critically, despite an emphasis on the adverse CEE outcomes, the ventricular volume findings in the transdermal $17 \beta$-estradiol group were similar to the CEE group but the effect just missed statistical significance $(p=0.06)$. Indeed, there were no differences in ventricular volume between CEE and $17 \beta$-estradiol groups, and their ventricular volumes were nearly identical at the end of the study.

Continued follow-up in KEEPS is warranted to determine the reproducibility of the cognitive and neuroimaging findings as women age and to address an issue of critical clinical importance that KEEPS is uniquely positioned to address. HT remains the standard treatment for moderate to severe vasomotor symptoms in women with no contraindications to HT. Approximately $28.5 \%$ of postmenopausal women younger than 55 years experience moderate to severe vasomotor symptoms, and these symptoms interfere with health- and work-related quality of life. ${ }^{3}$ Increased awareness of sex difference in Alzheimer disease underscores the need to identify sex-related risk factors for cognitive decline and dementia.

1. Espeland MA, Shumaker SA, Leng I, et al. Long-term effects on cognitive function of postmenopausal hormone therapy prescribed to women aged 50 to 55 years. JAMA Intern Med 2013;173:1429-1436.

2. Kantarci K, Tosakulwong N, Lesnick TG, et al. Effects of hormone therapy on brain structure: a randomized controlled trial. Neurology 2016;87:887-896.

3. Gartoulla P, Worsley R, Bell RJ, Davis SR. Moderate to severe vasomotor and sexual symptoms remain problematic for women aged 60 to 65 years. Menopause 2015;22: 694-701.

Pauline M. Maki, PhD

From the Departments of Psychiatry and Psychology, University of Illinois at Chicago.

Study funding: No targeted funding reported.

Disclosure: Pauline Maki served as a consultant for Noven Pharmaceuticals and Abbott. Go to Neurology.org for full disclosures
Among older women who received estrogen treatment in the WHIMS-MRI, lower regional brain volume was associated with greater cognitive decline or dementia. ${ }^{37}$ By contrast, we observed a change in brain structure over 4 years of hormone therapies that did not correlate with changes in cognitive function of recently menopausal women. The interpretation of this absence of an association between imaging findings and cognitive findings remains uncertain. On one hand, it is possible that the women who experienced structural brain changes with hormone therapies early in menopause will develop cognitive decline during an extended follow-up, and if proven, the imaging findings would be useful early surrogates of future clinical events. On the other hand, it is possible that these brain changes will subside after cessation of hormone therapy, and women who had structural brain changes during the 4 years of postmenopausal hormone therapy will not have an increased risk of cognitive decline over a longer follow-up. ${ }^{38}$ In the WHIMS-MRI studies, even though the brain volumes were smaller in women who received CEE therapies compared to placebo years after the end of the treatment phase, the rates of decline in brain volumes remained similar to the placebo group in the years following the cessation of CEE therapies. ${ }^{39}$ Thus, the short-term effects of estrogen treatment on the vascular system and on the brain may be different from long-term effects, and even opposed. Participants of the KEEPS-MRI study are being followed to determine whether these changes in brain structure are persistent after 4 years of hormone treatment and whether women with structural brain changes will develop clinically detectable cognitive decline.

\section{AUTHOR CONTRIBUTIONS}

Dr. Kantarci: design or conceptualization of the study, data collection, analysis and interpretation of the data, drafting the manuscript, study funding. Ms. Tosakulwong: analysis or interpretation of the data, revising the manuscript. Mr. Lesnick: analysis or interpretation of the data, revising the manuscript. Ms. Zuk: analysis or interpretation of the data, revising the manuscript. Dr. Gunter: analysis or interpretation of the data, revising the manuscript. Dr. Gleason: data collection, analysis or interpretation of the data, revising the manuscript. Dr. Wharton: data collection, analysis or interpretation of the data, revising the manuscript. Dr. Dowling: analysis or interpretation of the data, revising the manuscript. Dr. Vemuri: analysis or interpretation of the data, revising the manuscript. Mr. Senjem: analysis or interpretation of the data, revising the manuscript. Dr. Shuster: analysis or interpretation of the data, revising the manuscript. Dr. Bailey: analysis or interpretation of the data, revising the manuscript. Dr. Rocca: analysis or interpretation of the data, revising the manuscript. Dr. Jack: analysis or interpretation of the data, revising the manuscript. Dr. Asthana: data collection, analysis or interpretation of the data, revising the manuscript. Dr. Miller: design or conceptualization of the study, data collection, analysis or interpretation of the data, revising the manuscript, study funding.

\section{STUDY FUNDING}

This study is funded by the Aurora Foundation to the Kronos Longevity Research Institute and the NIH (NS66147, AG029624, and AG44170). The funding sources had no role in study design, collection, analysis, 
interpretation, or decision to submit this paper. The corresponding author had full access to all the data in the study and had final responsibility for the decision to submit for publication.

\section{DISCLOSURE}

K. Kantarci serves on the data safety monitoring board for Pfizer Inc., Takeda Global Research \& Development Center, Inc. She is funded by the NIH (R01AG040042, principal investigator [PI], R21 NS066147 [PI], Mayo Clinic Alzheimer's Disease Research Center/project 1 P50 AG16574/P1 [PI], P50 AG44170/project 2 [PI], and R01 AG11378 [coinvestigator]). N. Tosakulwong, T. Lesnick, S. Zuk, J. Gunter, C. Gleason, W. Wharton, and N. Dowling report no disclosures relevant to the manuscript. P. Vemuri is funded by the NIH M. Senjem holds stock in Gilead Sciences, Inc., Inovio Pharmaceuticals, Medtronic, Oncothyreon, Inc., and PAREXEL International. L. Shuster is funded by the NIH (P50 AG44170/core B [PI]). K. Bailey is funded by the NIH (P50 AG44170/core B [coinvestigator]). W. Rocca reports no disclosures relevant to the manuscript. C. Jack provides consulting services for Eli Lilly. He is funded by the NIH (R01-AG011378, RO1AG037551, U01-HL096917, U01-AG032438, U01-AG024904) and Alexander Family Alzheimer's Disease professorship of the Mayo Foundation. S. Asthana is funded by the NIH. V. Miller is funded by the NIA (P50 AG44170 [PI]). Go to Neurology.org for full disclosures.

Received June 17, 2015. Accepted in final form April 22, 2016.

\section{REFERENCES}

1. Shumaker SA, Reboussin BA, Espeland MA, et al. The Women's Health Initiative Memory Study (WHIMS): a trial of the effect of estrogen therapy in preventing and slowing the progression of dementia. Control Clin Trials 1998;19:604-621.

2. Espeland MA, Shumaker SA, Leng I, et al. Long-term effects on cognitive function of postmenopausal hormone therapy prescribed to women aged 50 to 55 years. JAMA Intern Med 2013;173:1429-1436.

3. LeBlanc ES, Janowsky J, Chan BK, Nelson HD. Hormone replacement therapy and cognition: systematic review and meta-analysis. JAMA 2001;285:1489-1499.

4. Prentice RL, Manson JE, Langer RD, et al. Benefits and risks of postmenopausal hormone therapy when it is initiated soon after menopause. Am J Epidemiol 2009;170:12-23.

5. Sherwin BB. Estrogen and memory in women: how can we reconcile the findings? Horm Behav 2005; 47:371-375.

6. Waring SC, Rocca WA, Petersen RC, O'Brien PC, Tangalos EG, Kokmen E. Postmenopausal estrogen replacement therapy and risk of $\mathrm{AD}$ : a population-based study. Neurology 1999;52:965-970.

7. Whitmer RA, Quesenberry CP, Zhou J, Yaffe K. Timing of hormone therapy and dementia: the critical window theory revisited. Ann Neurol 2011;69:163-169.

8. Yaffe K, Sawaya G, Lieberburg I, Grady D. Estrogen therapy in postmenopausal women: effects on cognitive function and dementia. JAMA 1998;279:688-695.

9. Zandi PP, Carlson MC, Plassman BL, et al. Hormone replacement therapy and incidence of Alzheimer disease in older women: the Cache County Study [see comment]. JAMA 2002;288:2123-2129.

10. Rocca WA, Grossardt BR, Shuster LT. Oophorectomy, estrogen, and dementia: a 2014 update. Mol Cell Endocrinol 2014;389:7-12.

11. Harman SM, Brinton EA, Cedars M, et al. KEEPS: the Kronos Early Estrogen Prevention Study. Climacteric 2005;8:3-12.

12. Harman SM, Black DM, Naftolin F, et al. Arterial imaging outcomes and cardiovascular risk factors in recently menopausal women: a randomized trial. Ann Intern Med 2014;161:249-260.

13. Gleason CE, Dowling NM, Wharton W, et al. Effects of hormone therapy on cognition and mood in recently postmenopausal women: findings from the KEEPS Cognitive and Affective Study. PLoS Med 2015;12:e1001833.

14. Jack CR Jr, Shiung MM, Gunter JL, et al. Comparison of different MRI brain atrophy rate measures with clinical disease progression in AD. Neurology 2004;62:591-600.

15. Dowling NM, Gleason CE, Manson JE, et al. Characterization of vascular disease risk in postmenopausal women and its association with cognitive performance. PLoS One 2013;8:e68741.

16. Gleason CE, Dowling NM, Wharton W, et al. Effects of hormone therapy on cognition and mood in recently postmenopausal women: findings from the randomized, controlled KEEPS-Cognitive and Affective Study. PLoS Med 2015;12:e1001833; discussion e1001833.

17. Gunter JL, Shiung MM, Manduca A, Jack CR Jr. Methodological considerations for measuring rates of brain atrophy. J Magn Reson Imaging 2003;18:16-24.

18. Fox NC, Cousens S, Scahill R, Harvey RJ, Rossor MN. Using serial registered brain magnetic resonance imaging to measure disease progression in Alzheimer disease: power calculations and estimates of sample size to detect treatment effects [see comment]. Arch Neurol 2000;57:339-344.

19. Raz L, Jayachandran M, Tosakulwong N, et al. Thrombogenic microvesicles and white matter hyperintensities in postmenopausal women. Neurology 2013;80:911-918.

20. Resnick SM, Espeland MA, Jaramillo SA, et al. Postmenopausal hormone therapy and regional brain volumes: the WHIMS-MRI Study. Neurology 2009;72:135-142.

21. Greenberg DL, Payne ME, MacFall JR, Provenzale JM, Steffens DC, Krishnan RR. Differences in brain volumes among males and female hormone-therapy users and nonusers. Psychiatry Res 2006;147:127-134.

22. Luoto R, Manolio T, Meilahn E, et al. Estrogen replacement therapy and MRI-demonstrated cerebral infarcts, white matter changes, and brain atrophy in older women: the Cardiovascular Health Study. J Am Geriatr Soc 2000;48:467-472.

23. Boccardi M, Ghidoni R, Govoni S, et al. Effects of hormone therapy on brain morphology of healthy postmenopausal women: a voxel-based morphometry study. Menopause 2006;13:584-591.

24. Eberling JL, Wu C, Haan MN, Mungas D, Buonocore M, Jagust WJ. Preliminary evidence that estrogen protects against age-related hippocampal atrophy. Neurobiol Aging 2003;24:725-732.

25. Ha DM, Xu J, Janowsky JS. Preliminary evidence that long-term estrogen use reduces white matter loss in aging. Neurobiol Aging 2007;28:1936-1940.

26. Lord C, Buss C, Lupien SJ, Pruessner JC. Hippocampal volumes are larger in postmenopausal women using estrogen therapy compared to past users, never users and men: a possible window of opportunity effect. Neurobiol Aging 2008;29:95-101.

27. Sowell ER, Peterson BS, Thompson PM, Welcome SE, Henkenius AL, Toga AW. Mapping cortical change across the human life span. Nat Neurosci 2003;6:309-315.

28. Kaye JA, Swihart T, Howieson D, et al. Volume loss of the hippocampus and temporal lobe in healthy elderly persons destined to develop dementia. Neurology 1997;48:12971304. 
29. Fox NC, Black RS, Gilman S, et al. Effects of Abeta immunization (AN1792) on MRI measures of cerebral volume in Alzheimer disease. Neurology 2005;64:15631572.

30. Grant R, Condon B, Lawrence A, et al. Is cranial CSF volume under hormonal influence? An MR study. J Comput Assist Tomogr 1988;12:36-39.

31. Protopopescu X, Butler T, Pan H, et al. Hippocampal structural changes across the menstrual cycle. Hippocampus 2008;18:985-988.

32. Pletzer B, Kronbichler M, Aichhorn M, Bergmann J, Ladurner G, Kerschbaum HH. Menstrual cycle and hormonal contraceptive use modulate human brain structure. Brain Res 2010;1348:55-62.

33. Young VG, Halliday GM, Kril JJ. Neuropathologic correlates of white matter hyperintensities. Neurology 2008;71: 804-811.

34. Kloppenborg RP, Nederkoorn PJ, Grool AM, et al. Cerebral small-vessel disease and progression of brain atrophy: the SMART-MR Study. Neurology 2012;79:2029-2036.
35. Jayachandran M, Litwiller RD, Owen WG, et al. Characterization of blood borne microparticles as markers of premature coronary calcification in newly menopausal women. Am J Physiol Heart Circ Physiol 2008;295: H931-H938.

36. Zhang QG, Han D, Wang RM, et al. C terminus of Hsc70-interacting protein (CHIP)-mediated degradation of hippocampal estrogen receptor-alpha and the critical period hypothesis of estrogen neuroprotection. Proc Natl Acad Sci USA 2011;108:E617-E624.

37. Espeland MA, Tindle HA, Bushnell CA, et al. Brain volumes, cognitive impairment, and conjugated equine estrogens. J Gerontol A Biol Sci Med Sci 2009;64:1243-1250.

38. LaCroix AZ, Chlebowski RT, Manson JE, et al. Health outcomes after stopping conjugated equine estrogens among postmenopausal women with prior hysterectomy: a randomized controlled trial. JAMA 2011;305:1305-1314.

39. Coker LH, Espeland MA, Hogan PE, et al. Change in brain and lesion volumes after CEE therapies: the WHIMS-MRI studies. Neurology 2014;82:427-434.

\section{Share Your Artistic Expressions in Neurology 'Visions'}

AAN members are urged to submit medically or scientifically related artistic images, such as photographs, photomicrographs, and paintings, to the "Visions" section of Neurology ${ }^{\circledR}$. These images are creative in nature, rather than the medically instructive images published in the NeuroImages section. The image or series of up to six images may be black and white or color and must fit into one published journal page. Accompanying description should be 100 words or less; the title should be a maximum of 96 characters including spaces and punctuation.

Learn more at www.aan.com/view/Visions, or upload a Visions submission at submit.neurology.org.

\section{Save These Dates for AAN CME Opportunities!}

Mark these dates on your calendar for exciting continuing education conferences by the American Academy of Neurology. Learn more at AAN.com/conferences.

\section{Fall Conference}

- October 14-16, 2016, Las Vegas, NV, at the Cosmopolitan of Las Vegas

Breakthroughs in Neurology

- January 13-16, 2017, Phoenix, AZ, at the Sheraton Grand at Wild Horse Pass

AAN Annual Meeting

- April 22-28, 2017, Boston, MA, at the Boston Convention Center 


\section{Neurology}

\section{Effects of hormone therapy on brain structure: A randomized controlled trial}

Kejal Kantarci, Nirubol Tosakulwong, Timothy G. Lesnick, et al.

Neurology 2016;87;887-896 Published Online before print July 29, 2016

DOI 10.1212/WNL.0000000000002970

\section{This information is current as of July 29, 2016}

\section{Updated Information \& Services \\ Supplementary Material}

\section{References}

Citations

Subspecialty Collections

Permissions \& Licensing

Reprints including high resolution figures, can be found at: http://n.neurology.org/content/87/9/887.full

Supplementary material can be found at: http://n.neurology.org/content/suppl/2016/07/29/WNL.0000000000002 970.DC1

http://n.neurology.org/content/suppl/2016/07/29/WNL.0000000000002 970.DC2

This article cites 39 articles, 10 of which you can access for free at: http://n.neurology.org/content/87/9/887.full\#ref-list-1

This article has been cited by 3 HighWire-hosted articles: http://n.neurology.org/content/87/9/887.full\#\#otherarticles

This article, along with others on similar topics, appears in the following collection(s):

\section{MRI}

http://n.neurology.org/cgi/collection/mri

Volumetric MRI

http://n.neurology.org/cgi/collection/volumetric_mri

Information about reproducing this article in parts (figures,tables) or in its entirety can be found online at:

http://www.neurology.org/about/about_the_journal\#permissions

Information about ordering reprints can be found online:

http://n.neurology.org/subscribers/advertise

Neurology ${ }^{\circledR}$ is the official journal of the American Academy of Neurology. Published continuously since 1951, it is now a weekly with 48 issues per year. Copyright @ 2016 American Academy of Neurology. All rights reserved. Print ISSN: 0028-3878. Online ISSN: 1526-632X.

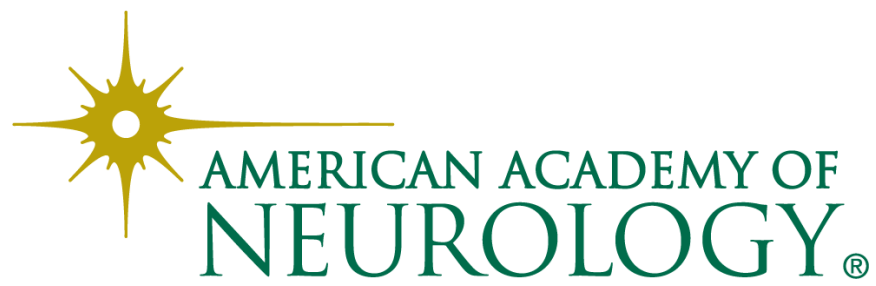

